\title{
EDITORIAL
}

\section{The resilience of forest fragmentation genetics-no longer a paradox - we were just looking in the wrong place}

\author{
Heredity (2015) 115, 97-99; doi:10.1038/hdy.2015.40
}

Over the past decade, several studies and reviews have documented the apparent resilience of widespread tree species to the population genetic consequences of habitat fragmentation and disturbance (for example, Lowe et al., 2005; Lowe, 2005; Kramer et al., 2008; Bacles and Jump, 2010). Classically, under conservation genetic principles, decreases in population size and density of trees, caused by habitat fragmentation and disturbance activities such as logging, are expected to reduce genetic diversity, increase genetic differentiation and potentially increase inbreeding (Lowe et al., 2004). Yet a large number of forest tree species are able to ameliorate these population genetic pressures through a variety of mechanisms. The first is through extensive gene flow via pollen and/or seed (in many cases over $10 \mathrm{~s}$ of $\mathrm{km}$; e.g. White et al., 2002; Bacles et al., 2005), which can maintain connectivity even in highly fragmented and degraded landscapes where trees persist at very low densities in matrices of varied land use (for example, Breed et al., 2011; Lander et al., 2011). The second is due to the long-lived nature of trees and the existence of overlapping generations on single sites that serves to retard the loss of genetic diversity (for example, Lowe et al., 2005; Petit and Hampe, 2006; Bacles and Jump, 2010; Davies et al., 2010). Thirdly, flexible mating systems in some species can circumvent self-incompatibility to allow selfed progeny to form (Ward et al., 2005), particularly when faced with an Allee effect (lack of compatible mates within a landscape).

In the decade since a previous focal issue of Heredity on this topic (Lowe, 2005), research to examine the resilience of forest trees to the genetic impacts of fragmentation have included assessments of gene flow dynamics (for example, Bacles et al., 2006; Hardesty et al., 2006; Ottewell et al., 2009), spatial genetic structure and cohort formation in natural populations (for example, Cavers et al., 2005; Hardesty et al., 2005; Kremer et al., 2005; Luna et al., 2005), comparisons of genetic diversity in pre-disturbance adult populations versus post-disturbance seedling populations (Kettle et al., 2007), and analysis of the mating system and fitness consequences of low mate availability (for example, Breed et al., 2012a,b).

As perhaps could have been predicted, the past 10 years of study have shown that forest trees are not completely resilient to the population genetic consequences of forest fragmentation. Rather impacts vary by species and context, and are more nuanced than simple losses of genetic diversity and increased differentiation among populations. For example, some of the key consequences of forest fragmentation have now been identified as increased inbreeding depression in progeny sired in a fragmented landscape (for example, Breed et al., 2012b) and genetic diversity and fitness loss due to low numbers of mating partners and low pollen diversity (for example, Breed et al., 2012a, 2014).

In this latest focal issue of Heredity we introduce five important studies of neotropical trees and eucalypts (Breed et al., 2015a,b; Davies et al., 2015; Rymer et al., 2015; Vinson et al., 2015) that further advance our understanding of forest fragmentation genetics, and are described below. Overall, from these and other recent studies, our understanding of forest fragmentation genetics has developed in three key areas. First, it can be argued that in focusing on adult populations to understand the population genetic and fitness consequences of forest fragmentation, we have been looking in the wrong place. Instead, we need to focus attention on the progeny sired in impacted landscapes and their relative success in regenerating in a range of conditions. Second, we now understand that variation in mating and breeding systems is an important factor determining the type and magnitude of response. Third, the specific landscape context (for example, scale and land-use type) and nature of impact (for example, fragmentation versus logging) are also important variables influencing response. A continued focus on these three areas is likely to be scientifically fruitful and deliver real progress on management strategies for trees in impacted landscapes. In particular, a more quantitative approach to linking changes in pollination to mating systems to fitness is likely to yield important insights on the mechanisms driving the changes we observe (for example, Vanbergen et al., 2013). We look forward to reviewing new hypotheses, developments and latest research in this area in 10 years time!

\section{OVERVIEW OF THE FOCAL ISSUE STUDIES}

The first study (Breed et al., 2015a) takes as its context the global problem of changing pollinator availability and dynamics in fragmented landscapes. With many tree species being animal pollinated (at least in tropical systems), the genetic diversity and fitness of progeny of woody plants sired in fragmented landscapes are expected to decline due to shifts in plant-mating patterns (for example, reduced outcrossing rate and/or pollen diversity due to habitat fragmentation and/or changes in pollinator community composition and behavior, Vanbergen et al., 2013). This hypothesis is tested by Breed et al. (2015a) in a case study of three ecologically divergent Eucalyptus tree species, and from a meta-analysis of the literature. For the two eucalypts pollinated by small insects, increased selfing and decreased pollen diversity was correlated with increased fragmentation, but no such relationship was evident for the eucalypt species pollinated by a mobile bird. In a meta-analysis of forest tree studies across all ecosystems, habitat fragmentation was observed to be generally correlated with decreased pollen diversity and increased selfing rates in progeny, but more mobile pollinators (for example, birds) tend to dampen these mating-pattern shifts. Thus habitat fragmentation was found to generally have a negative impact on the diversity and inbreeding levels in progeny, but this impact was greater in tree species with less mobile pollinators.

The second study asks whether some forest contexts are more sensitive than others to population genetic impacts (Davies et al., 2015). During the colonization of open landscapes, seed-source 
bottlenecks can cause a severe reduction in genetic diversity and is particularly an issue for secondary forest colonizing trees (Davies et al., 2010). Under these conditions, pollinator behavior is expected to be impacted by the great variation in tree density between old growth (low density) and secondary forest (high density). These assumptions are tested for the long-lived, self-compatible pioneer tree, Vochysia ferruginea, at old growth and secondary forest sites in Costa Rica (Davies et al., 2015). Progeny from both old growth and secondary forest contexts were predominantly outcrossed and experienced low levels of biparental inbreeding, indicating that the mating patterns of $V$. ferruginea are relatively robust to density differences between old growth and secondary forest stands. In addition, pollen-mediated gene flow potentially maintained genetic diversity of open-pollinated progeny arrays in stands of secondary forest adults. These results highlight the importance of conserving primary forest remnants within fragmented landscapes, as they appear directly to promote maintenance of genetic diversity during forest regeneration.

The third study examines the issue of habitat fragmentation disrupting ecosystem processes such as plant-pollinator mutualisms (Ottewell et al., 2009; Breed et al., 2012a). When such processes are disrupted, mating patterns in remnant tree populations are expected to shift toward increased inbreeding and reduced pollen diversity, with negative fitness consequences for future generations (Breed et al., 2012b). However, assessments of mating patterns and the fitness of open-pollinated progeny have rarely been combined in a single study (although see Fuchs et al., 2003). Breed et al. (2015b) collected openpollinated seeds of Eucalyptus incrassata trees from contrasting stand densities (intact woodland versus isolated pasture trees) and assessed genetic diversity of pollen, pollen flow and mating patterns, as well as early stage progeny viability. Tree species population density had no impact on mating patterns, adult and progeny genetic diversity, or progeny growth, but was associated with increased mean pollen dispersal. There was evidence for inbreeding depression, apparent as stress-related fungal infection, but this was not associated with density. E. incrassata appears to be resistant to the negative mating and fitness changes expected within fragmented landscapes, probably due to strong outcrossing and regular long-distance pollen flow.

The fourth study examines the suitability of remnant trees as seed sources in agricultural landscapes and their potential role in facilitating pollen flow between fragments, both of which have been provoked much previous discussion (for example, Lowe et al., 2005; Breed et al., 2011; Lander et al., 2011; Breed et al., 2012b). Rymer et al. (2015) contrast the mating patterns of bat-pollinated Pachira quinata trees in continuous forest versus isolated trees in pasture systems. Although pasture trees experienced some of the longest distance mating events, overall they had higher inbreeding rates and fewer sires than those in continuous forests. A leaky self-incompatibility system was observed, with self-pollen having reduced germination on stigmas and slower growth rate through the style, though some trees were incapable of selfing. Self-pollination resulted in lower seed set, germination and seedling growth compared with outcrossed progeny. Thus while remnant trees in agricultural landscapes were involved in broader mating patterns, they showed increased but highly variable levels of inbreeding, which resulted in net reduction in progeny fitness.

The fifth study (Vinson et al., 2015) used modeling and empirical data from a large-scale experiment to assess the long-term impact of selective logging on two Amazonian rainforest trees with contrasting life histories. Dipteryx odorata is a slow growing climax tree, which occurs at very low densities, whereas Jacaranda copaia is a fast growing pioneer tree that occurs at high densities. In long-term (300 years) simulations, current Brazilian forest management regulations were sufficient to maintain populations of J. copaia but led to a dramatic decline in $D$. odorata populations unless the minimum cutting diameter was increased from 50 to $100 \mathrm{~cm}$ over 30-year logging cycles. By contrast, genetic parameters were only slightly affected by selective logging in these simulations, with minor reductions in the numbers of alleles and genotypes. In the short term, the loss of alleles from observed and simulated populations of J. copaia corresponded, whereas real populations of $D$. odorata lost greater diversity than simulated systems. Crucially, forest fragmentation may increase the scale of long-term genetic impacts of selective logging in D. odorata through reduced gene flow and effective population size. The different impacts and periods of recovery for each species supported the idea that ecological and genetic information at species, ecological guild or reproductive group levels are essential to help derive sustainable management scenarios for tropical forests, and argue against a 'one size fits all' policy.

\section{CONFLICT OF INTEREST}

The authors declare no conflict of interest.

\section{ACKNOWLEDGEMENTS}

We thank all contributors to this focal issue. This research was supported by EU funding through the INCO-DEV program and for the project SEEDSOURCE and from the Australian Research Council (LP110200805 awarded to AJL; DE150100542 awarded to MFB; DP150103414 awarded to AJL and MFB).

A J Lowe ${ }^{1}$, S Cavers $^{2}$, D Boshier $^{3}, \mathrm{M} \mathrm{F} \mathrm{Breed}^{1}$ and P M Hollingsworth ${ }^{4}$ ${ }^{1}$ Australian Centre of Evolutionary Biology and Biodiversity, Environment Institute, School of Biological Sciences, University of Adelaide, North Terrace, South Australia, Australia; ${ }^{2}$ Centre for Ecology and Hydrology-Edinburgh, Bush Estate, Penicuik, UK; ${ }^{3}$ Department of Plant Sciences, University of Oxford, Oxford, UK and ${ }^{4}$ Royal Botanic Garden-Edinburgh, Inverleith Row, Edinburgh, UK E-mail: andrew.lowe@adelaide.edu.au

Bacles CFE, Jump AS (2010). Taking a tree's perspective on forest fragmentation genetics. Trends Plant Sci 16: 13-18.

Bacles CFE, Lowe AJ, Ennos RA (2006). Seed dispersal across a fragmented landscape. Science 311: 628.

Bacles CFE, Burczyk J, Lowe AJ, Ennos RA (2005). Historical and contemporary mating patterns in remnant populations of the forest tree Fraxinus excelsior L. Evolution 59: 979-990.

Breed MF, Ottewell KM, Gardner MG, Marklund MHK, Dormontt EE, Lowe AJ (2015a) Mating patterns and pollinator mobility are critical traits in forest fragmentation genetics. Heredity (Edinb) 115: 108-114.

Breed MF, Ottewell KM, Gardner MG, Marklund MHK, Stead MG, Harris JBC et al. (2015b). Mating system and early viability resistance to habitat fragmentation in a birdpollinated eucalypt. Heredity (Edinb) 115: 100-107.

Breed MF, Christmas MJ, Lowe AJ (2014). Higher levels of multiple paternities increase seedling survival in the long-lived tree Eucalyptus gracilis. PLOS ONE 9: e90478.

Breed MF, Marklund MHK, Ottewell KM, Gardner MG, Harris JBC, Lowe AJ (2012a). Pollen diversity matters: revealing the neglected effect of pollen diversity on fitness in fragmented landscapes. Mol Ecol 21: 5955-5968.

Breed MF, Gardner MG, Ottewell KM, Navarro CM, Lowe AJ (2012b). Changing trade-offs between inbreeding costs and reproductive assurance in Central American big-leaf mahogany (Swietenia macrophylla). Ecol Lett 15: 444-452.

Breed MF, Ottewell K, Gardner MG, Lowe AJ (2011). Clarifying climate change adaptation responses for scattered trees in modified landscapes. J Appl Ecol 48: 637-641.

Cavers S, Degen B, Caron H, Hardy O, Lemes M, Gribel R et al. (2005). Optimal sampling strategy for estimation of spatial genetic structure in tree populations. Heredity 95: 281-289.

Davies SJ, Cavers S, Finegan B, White A, Breed MF, Lowe AJ (2015). Pollen flow in fragmented landscapes maintains genetic diversity following stand-replacing disturbance in a neotropical pioneer tree, Vochysia ferruginea. Heredity 115: 125-129.

Davies SJ, Cavers S, Finegan B, Navarro C, Lowe AJ (2010). Genetic consequences of multigenerational and landscape colonisation bottlenecks for a neotropical forest pioneer tree, Vochysia ferruginea. Tropical Plant Biology 3: 14-27. 
Fuchs EJ, Lobo JA, Quesada M (2003). Effects of forest fragmentation and flowering phenology on the reproductive success and mating patterns of the tropical dry forest tree Pachira quinata. Conserv Biol 17: 149-157.

Hardesty BD, Hubbell SP, Bermingham E (2006). Genetic evidence of frequent longdistance recruitment in a vertebrate-dispersed tree. Ecol Lett 9: 516-525.

Hardesty BD, Dick CW, Kremer A, Hubbell S, Bermingham E (2005). Spatial genetic structure of Simarouba amara Aubl. (Simaroubaceae), a dioecious, animal-dispersed Neotropical tree, on Barro Colorado Island, Panama. Heredity 95: 290-297.

Kettle CJ, Hollingsworth PM, Jaffré T, Moran B, Ennos RA (2007). Identifying the early genetic consequences of habitat degradation in a highly threatened tropical conifer, Araucaria nemorosa de Laub. Mol Ecol 16: 3581-3591.

Kramer AT, Ison AJ, Ashley MV, Howe HF (2008). The paradox of forest fragmentation genetics. Conserv Biol 22: 878-885.

Kremer A, Caron H, Cavers S, Colpaert N, Gheysen L, Gribel R et al. (2005). Monitoring genetic diversity in tropical trees with multilocus dominant markers. Heredity 95 : 274-280.

Lander TA, Bebber D, Choy TL, Harris SA, Boshier DH (2011). The Circe Principle explains how resource-rich land can waylay pollinators in fragmented landscapes. Curr Bio/ 21 $1302-1307$

Lowe A (2005). Population genetics of neotropical trees focus issue. Heredity 95: 243-245.

Lowe AJ, Boshier D, Ward M, Bacles CFE, Navarro C (2005). Genetic resource loss following habitat fragmentation and degradation; reconciling predicted theory with empirical evidence. Heredity 95: 255-273.
Lowe AJ, Harris SA, Ashton P (2004). Ecological Genetics: Design, Analysis and Application. Blackwell: Oxford, UK, p 326.

Luna R, Epperson BK, Oyama K (2005). Spatial genetic structure of two sympatric neotropical palms with contrasting life histories. Heredity 95: 298-305.

Ottewell KM, Donnellan SC, Lowe AJ, Paton DC (2009). Predicting reproductive success of insect- versus bird-pollinated scattered trees in agricultural landscapes. Biol Conserv 142: 888-898.

Petit RJ, Hampe A (2006). Some evolutionary consequences of being a tree. Annu Rev Ecol Evol Syst 37: 187-214.

Rymer PD, Sandiford M, Harris SA, Billingham MR, Boshier DH (2015). Remnant Pachira quinata pasture trees have greater opportunities to self and suffer reduced reproductive success due to inbreeding depression. Heredity 115: 115-124.

Vanbergen AJ, Woodcock BA, Gray A, Grant F, Telford A, Lambdon P et al. (2013). Grazing modifies insect visitation networks and plant mating systems. Funct Ecol 28: 178-189.

Vinson CC, Kanashiro M, Sebbenn AM, Williams TCR, Harris SA, Boshier DH (2015). Long-term impacts of selective logging on two Amazonian tree species with contrasting ecological and reproductive characteristics: inferences from Eco-gene model simulations. Heredity 115: 130-139.

White G, Boshier D, Powell W (2002). Increased pollen flow counteracts fragmentation in a tropical dry forest: An example from Swietenia humilis Zuccarini. Proc Natl Acad Sci USA 99: 2038-2042.

Ward M, Dick CW, Gribel R, Lemes M, Caron H, Lowe AJ (2005). To inbreed, or not to inbreed: a review of mating systems and pollen dispersal variance in neotropical trees. Heredity 95: 246-254. 